\title{
Integral Equations: The Concept Of Integrals
}

\author{
Mr. Chetan Ambekar \\ K. J. Somaiya College of Engineering University Of Mumbai, India.
}

\begin{abstract}
The use of the double integral is the topic of the paper. The link of the double integral and the single integral is mentioned and the splitting of the double integral in two simple single integrals is involved. Also the equation of the curve formed when the double integral is converted to a single in integral is mentioned.

The paper deals with the question that if the double integral is solved and it is converted to single integral then what is ment by it, also the equation of the curve formed of that single integral function is discussed and the relation between the surface of that double integral function and the single integral function is discussed.
\end{abstract}

\section{Introduction}

This paper deals with the DOUBLE INTEGRALS as what does double integral mean to me. It also consist of some facts and the proofs which provides the relation between the double integral and the single integral.

We have the function as

$\mathrm{Y}=\mathrm{f}(\mathrm{x}, \mathrm{y})$

Generally, we have to plot or to calculate area under the curve of this region we have to take the double integral of the function

Therefore,

$\mathrm{z}=\iint \mathrm{f}(\mathrm{x}, \mathrm{y}) \mathrm{d}(\mathrm{x}) \mathrm{d}(\mathrm{y})$

Solve the double in integral and convert the function to a single integral function generally

We have

$\mathrm{Z}=\int \mathrm{g}(\mathrm{x}) \mathrm{dx} \quad$ or $\quad \mathrm{Z}=\int \mathrm{g}(\mathrm{y}) \mathrm{dy} \quad \ldots$ eq. (1)

Depending on the term or the parameter ( $\mathrm{x}$ or $\mathrm{y}$ ) we keep constant the value of the integral will change as shown in the eq. 1.

The relation between the $\mathrm{f}(\mathrm{x}, \mathrm{y})$ and $\mathrm{g}(\mathrm{x})$ or the relation between the $\mathrm{f}(\mathrm{x}, \mathrm{y})$ and $\mathrm{g}(\mathrm{y})$ is described in this paper. We are known to the single integral function as it can be written and described using the limits as the sum.

We have $\int_{a}^{b} f(x) d x=\sum_{r=1}^{n} f(t)$

This concept can be extended further to define the integral of functions of two independent variables as follows. DOUBLE INTEGRATION : DEFINATION

Let $f(x, y)$ be a continuous function and it is single valued of two variables $x, y$ defined over a region $R$ of area A bounded by a closed simple curve $\mathrm{C}$. let the region be divided into $\mathrm{n}$ sub intervals in any manner (eg. By drawing horizontal and the vertical lines) into sub regions $\mathrm{R} 1, \ldots \mathrm{R} 4$ $\mathrm{Rn}$ of areas $\mathrm{A} 1, \ldots . . \mathrm{A} 4, \ldots \ldots . \mathrm{An}$.

Let $\mathrm{P}(\mathrm{Xr}, \mathrm{Yr})$ be any point inside the rth sub region of area $\mathrm{Ar}$.

We know form the sum

$\mathrm{f}(\mathrm{x} 1, \mathrm{y} 1) \& \mathrm{~A}+\ldots \ldots \ldots \ldots . . \mathrm{f}(\mathrm{x} 7, \mathrm{y} 7) \& \mathrm{~A}+$ $+\mathrm{f}(\mathrm{xn}, \mathrm{yn})$

ie. $\sum_{\mathrm{r}=1}^{\mathrm{n}} \mathrm{f}(\mathrm{xr}, \mathrm{yr}) \& A r$.

We now increase the number of sub regions such that the area of each sub region becomes smaller and smaller. The limit of the sum (1), when it exits, as tends to infinity and the area of each sub intervals tend to zero is called the double integral of the $\mathrm{f}(\mathrm{x}, \mathrm{y})$ over the region $\mathrm{A}$ and is denoted by

$\iint_{A} f(x, y) d x d y$.

Thus, $\iint_{\mathrm{A}} \mathrm{f}(\mathrm{x}, \mathrm{y}) \mathrm{dxdy}=\lim \sum_{\mathrm{r}=1}^{\mathrm{n}} \mathrm{f}(\mathrm{x}, \mathrm{y}) \& A$

\section{EQUATION OF DOUBLE INTEGRAL :}

The double integral as defined above can be evaluated by successive single integration as follows:

If $\mathrm{A}$ is a region bounded by the curves $\mathrm{y}=\mathrm{f}(\mathrm{x}), \mathrm{y}=\mathrm{g}(\mathrm{x})$.

Then,

$\iint f(x, y) d(x) d(y)=\int_{a}^{b} \int_{f(x)}^{g(x)} f(x, y) d y d x$.

Where the integration w.r.t. $y$ is performed first by treating $x$ as constant.

Consider the area bounded the two curves $y=f(x)$ and $y=g(x)$ and the ordinates as $x=a$ and $x=b$. 
Now consider a strip parallel to the axis. On this strip y varies from $y=f(x)$ to $y=g(x)$. if the strip is moved to itself so that it will sweep the shown area then $\mathrm{x}$ varies from $\mathrm{a}$ and $\mathrm{b}$. now it can be shown that $\iint f(x, y) d(x) d(y)=\int_{a}^{b} \int_{f(x)}^{g(x)} f(x, y) d y d x$.

\section{1 .}

\section{Concept}

Generally to find the double integral of any function $f(x, y)$ we have to first convert the double integral to the single integral. So in order to convert to the single integral we have to take solve by using one variable constant as $\mathrm{x}$ or $\mathrm{y}$.

\subsection{CONVERSION:}

When we have the tendency to convert the double integral to single integral .

Let $f(x, y)$ be a function of independent variables $x$ and $y$. we have to convert in single integral there we take the cases in which we first consider $\mathrm{x}$ as constant and $\mathrm{y}$ as independent variable.

Therefore

$$
\int_{a}^{b} \int_{f 1(x)}^{f 2(x)} f(x, y) d x d y=
$$

Here the function varies from $\mathrm{x}=\mathrm{a}$ to $\mathrm{x}=\mathrm{b}$ and $\mathrm{y}=\mathrm{f} 1(\mathrm{x})$ to $\mathrm{y}=\mathrm{f} 2(\mathrm{x})$. so we take the $\mathrm{x}$ is independent and $\mathrm{y}$ as dependent of $\mathrm{x}$.

\subsection{Plotting of curve:}

Plot the curve $y=f 1(x)$ and $y=f 2(x)$ on the $x-y$ plane and find its required region according to specified values of $\mathrm{x}$ that is $\mathrm{a}$ and $\mathrm{b}$.

We take the integration of the curve according to the limits decided by the $\mathrm{y}$ as $\mathrm{f} 1(\mathrm{x})$ and $\mathrm{f} 2(\mathrm{x})$.

We got

And what actually $\mathrm{g}(\mathrm{x})$ is,

$$
\int_{a}^{b} g(x) d x
$$

we know that limits of $y$ are the extension of the curve $f 1(x)$ and $f 2(x)$ in the $y$ direction. when the region enclosed between the curves the closed curve must have to be integrated in the $\mathrm{x}$ direction for getting the double integral.

In this case the curve $\mathrm{g}(\mathrm{x})$ is actually a line which is parallel to $\mathrm{y}$ - axis as the line is made to integrated over $\mathrm{x}=\mathrm{a}$ to $\mathrm{x}=\mathrm{b}$.

\subsection{AREA}

In the simple integral we have to take the area under the curve of the whole region. Similarly we have the equation of the line here and it has been integrated in the prescribed limits.

Actually the line about which we are talking is the centroidal line which passes from the centroid of the curve and parallel to y-axis.

Here the curve explains the the change in the $\mathrm{x}$ as there is a enclosed figure $\mathrm{ABCD}$ and the $\mathrm{x}$ varies from $\mathrm{x} 1$ to $\mathrm{x} 2$.

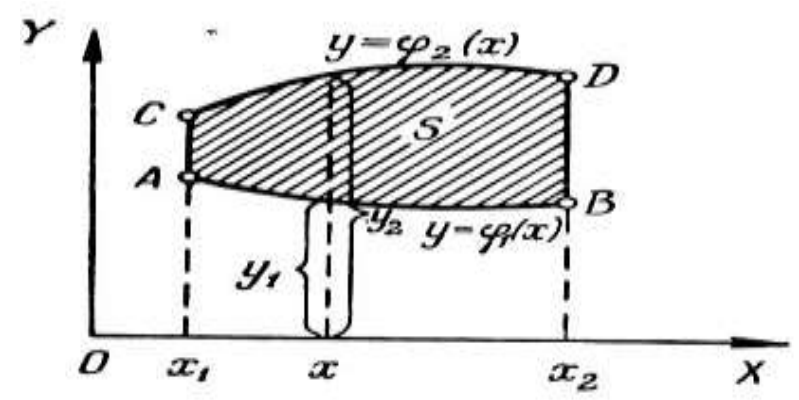

\section{Change In Varible:}

Consider the second case when the $\mathrm{x}$ is dependent on $\mathrm{y}$ and $\mathrm{y}$ is a dependent variable.

1.2 TAKING $X$ AS VARIBLE:

Similarly we have the same curve as $f(x, y)$ so here we will integrate the $x$ first as it is a dependent variable and then y over the prescribed limits 
So we will first integrate by taking $\mathrm{x}$ as variable. So we get

$$
\int_{a}^{b} \int_{f 1(y)}^{f 2(y)} f(x, y) d y d x=
$$

$$
\int_{a}^{b} g(y) d y
$$

Here the curve $\mathrm{g}(\mathrm{y})$ is a line which is parallel to $\mathrm{x}$ axis which has to be integrated along the $\mathrm{y}$ axis limits that is from $\mathrm{y}=\mathrm{a}$ to $\mathrm{y}=\mathrm{b}$.

Actually the line about which we are talking is the centroidal line which passes from the centroid of the curve and parallel to $\mathrm{x}$-axis.

\subsection{PLOTTING OF FIGURE:}

Here the figure explains the variation of $\mathrm{y}$ from $\mathrm{y} 1$ to $\mathrm{y} 2$ along the figure $\mathrm{ABCD}$ as here the $\mathrm{x}$ varies from $\mathrm{y} 1$ to y2.

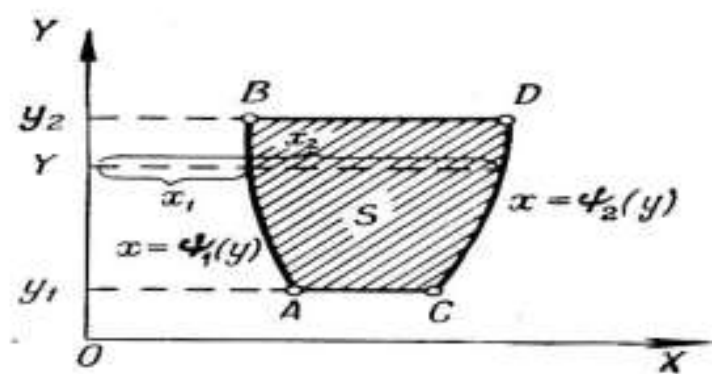

Now consider the case of triple integral in this case we have three variables $\mathrm{x}, \mathrm{y}$ and $\mathrm{z}$.

Then take the case in which we have

$$
\int_{a}^{b} \int_{f 1(x)}^{f 2(x)} \int_{g 1(x, y)}^{g 2(x, y)} f(x, y, z) d x d y d z
$$

\section{TRIPLE INTEGRAL:}

The in this case we can have two curves as if we convert the triple integration to a double integral considering either $\mathrm{x}$ or $\mathrm{y}$ or $\mathrm{z}$ as constant variable and the other as the dependent variable.

\subsection{CONVERSION TO DOUBLE INTEGRALS:}

So if we convert in double integral then,

$$
\int_{a}^{b} \int_{f 1(x)}^{f 2(x)} m(x, y) d x d y \quad \text { e.q. } 2
$$

Here the $f(x, y, z)$ is actually a space region or we can say a three dimensional space. Also we can say that the function $\mathrm{m}(\mathrm{x}, \mathrm{y})$ is the plane which is actually parallel to $\mathrm{x}-\mathrm{y}$ plane.

\subsection{CONVERSION TO SINGLE INTEGRAL:}

Also again if again we convert the equation in to single integral then again we can say that it is a equation of a line parallel to axis either $\mathrm{x}$ or $\mathrm{y}$ depending on the dependent variable.

If we write the equation 2 as

$\int_{a}^{b} \int_{f 1(y)}^{f 2(y)} m(y, z) d y d z$

Then we say that the dependent variable here is $\mathrm{x}$ and the curve $\mathrm{m}(\mathrm{y}, \mathrm{z})$ is parallel to the $\mathrm{y}-\mathrm{z}$ plane and also passes from the centroidal plane of that region. Again taking the integral and converting to single integral then the curve is parallel to any axis depending to the variable which is dependent, if the dependent variable is y then the curve formed is parallel to y axis otherwise $\mathrm{x}$-axis.

\subsection{CHANGE IN VARIBLES:}

Similarly we can define the other condition

$$
\int_{a}^{b} \int_{f 1(x)}^{f 2(x)} m(x, z) d x d z
$$

2.4 Here dependent variable is $\mathrm{y}$ and the curve $\mathrm{m}(\mathrm{x}, \mathrm{z})$ is parallel to the plane $\mathrm{x}-\mathrm{z}$ and also passes from the centroidal plane of the three dimensional space. again taking the integral then we convert to single integral then the curve is again a line parallel to any axis depending on the dependent variable. 


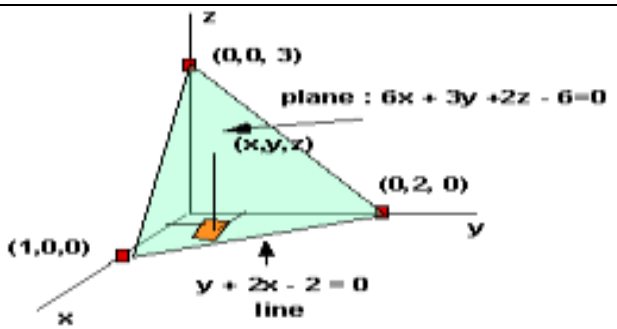

Here the case is taken in which the plane is formed by the three equations and also the plane formed by theequation when there is the case of forming the double integrels then the the plane is parallel to the main $x-y-z$ plane and passes from the centroid of the figure .

\section{APPLICATION ON NTH INTEGRAL:}

This condition of applying the concept can be used for nth integral as in this case let we have there is nth dimensional plane and if we take the integral of that then the curve which is formed is nothing but the figure which actually consists of the centroidal figure of the main nth degree equation figure.

$$
\int_{a}^{b} \int_{f 1(x)}^{f 2(x)} \ldots \ldots \ldots \ldots \ldots \int_{b(x, y, z \ldots \ldots)}^{b 2(x, y, z \ldots \ldots \ldots)} f(x, y, z, \ldots \ldots) d x d y d z \ldots \ldots \ldots
$$

Then if we take integral of this case then the figure we get, is the figure which covers the centroidal figure of the main figure and parallel to any of the figure formed by the mixture of the independent variables.

\section{Conclusion}

This paper consist of the method through which we can relate the concept of integrals to the mechanics. If we solve the integral then the figure we get, is the figure which covers the centroidal figure of the main figure and parallel to any of the figure formed by the mixture of the independent variables.

This concept is applied in the various fields of mechanics and fluid mechanics.

There can be certain limitations to this concept as it is difficult to analyze the figure regarding the nth order integral when in the future when the nth dimension will be defined this concept can be applied there for finding out the center of gravity etc.

\section{Aknowledgement}

I Want To Thank All The Professors PROF. ALGONDA DESAI, PROF. YOGESH THAKKAR Etc. Who Helped Me For Preparing Me This Journal Paper. I Want To Thank My Friend MAS. SUJIT RANJAN, MAS. RAHUL KESAN, MAS. PRAKHAR AWASTHI And All My Hostel Mates For Helping Me A Lot.

\section{References}

[1] www. tutorial.math.lamar.edu

[2] www. people.rit.edu

\section{REFERENCE AUTHORS :}

[3] PROF. RAMANNA, M.SC. MATHEMATICS (HONS), ENGINEERING MATHEMATICS.

[4] PROF. ALGONDA DESAI, M.SC. MATHEMATICS

[5] PROF. P. WARTIKER, HIGHER ENGINEERING MATHEMATICS

[6] Dr. B. S. GAREWAL, HIGHER ENGINEERING MATHEMATICS, KHANNA PUBLISHERS, DELHI.

[7] DR. SRIVASTAVA, ENGINEERING MATHEMATICS -2. 